IJBPAS, December, Special Issue, 2021, 10(12): 396-423

ISSN: 2277-4998

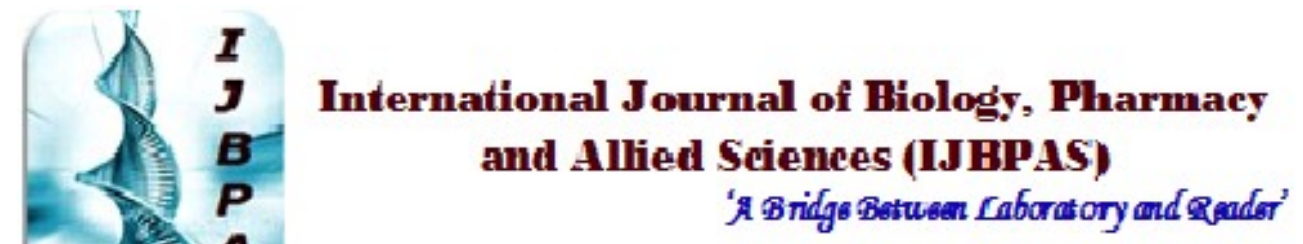

www.ibpas.com

\title{
A REVIEW ON SESBANIA GRANDIFLORA USED IN THE TREATMENT OF DEMENTIA
}

\author{
SHARAD SHARMA ${ }^{1 *}$, BHUPESH C. SEMWAL ${ }^{1}$, KAMAL SHAH ${ }^{1}$, SHAILESH \\ PATHAK $^{2}$, SUNIL KUMAR TIWARI ${ }^{2}$, SOMENDRA KUMAR MAURYA ${ }^{3}$
}

1: GLA University,NH-2, Mathura-Delhi Road Mathura, U.P- 281406

2: Jyotiraditya Institute of Pharmacy, Pratapgarh, U.P-230401

3: Shri Guru Ram Rai University, Dehradun, Uttarakhand, 248001

*Corresponding Author: Sharad Sharma: E Mail: me.sharadsharma@rediff.com

Received 19 ${ }^{\text {th }}$ Aug. 2021; Revised 20 ${ }^{\text {th }}$ Sept. 2021; Accepted 29 ${ }^{\text {th }}$ Oct. 2021; Available online $1^{\text {st }}$ Dec. 2021

https://doi.org/10.31032/IJBPAS/2021/10.12.2038

\begin{abstract}
Family Leguminosae's Sesbania grandiflora is rich in sterols, saponins, and tannins, which give it a wide range of medicinal benefits. Roots, bark, leaves, flowers, and fruits are only some of the plant components that have been studied for their unique pharmacological effects. Tannins, flavonoids, coumarins, steroids, triterpenes, and isovestitol, and medicarpin are all found in high concentrations in the plant, as is satan betulinic acid. Sesbania grandiflora can be used alone or with other herbs to treat a wide range of diseases. Dementia is a loss of cognitive ability that impairs daily activities and daily routines. One to four percent of the world's population over 65 has some kind of Dementia, a set of degenerative disorders involving brain cells degenerating. A variety of different etiologies causes Alzheimer's disease. Heart illness and neurodegenerative conditions (such as hypertension, hypercholesteremia, and diabetes) put patients at greater risk of Dementia. Other risk factors for this neurodegenerative disease include excessive alcohol usage and smoking. Alzheimer's disease, vascular Dementia, frontotemporal Dementia, semantic Dementia, and Dementia with Lewy bodies are the most frequent types of Dementia. The elderly are more likely to develop Alzheimer's disease or Dementia with Lewy bodies. Long-term cardiovascular disease (CVS) can trigger Vascular Dementia (VaD), the second most frequent form of Dementia after Alzheimer's disease (AD). Dementia with semantic memory loss is referred to as semantic
\end{abstract}


Dementia (knowledge of objects, people, concepts, and words). Aggregation of synuclein hinders neuronal growth in Lewy body dementia (LBD) and is critical in the disease's pathophysiology. For this review, we looked at the effectiveness of Sesbania grandiflora in treating Dementia. Dementia-treating various medicinal plants are described in this article.

Keywords: Dementia, Alzheimer's disease, Sesbania grandiflora, Antioxidant, Phytochemicals INTRODUCTION:

Dementia is characterized by a progressive decrease in memory and cognitive loss. The symptomatic usage of acetylcholine esterase inhibitors (AchEI) and the short-lived noneffective N-methyl-D aspartate memantine are currently available for AD therapy. Alzheimer's disease is related to the most common cause of memory impairment and cognitive dysfunction in the elderly. Alzheimer's disease (AD) means that neurons degenerate gradually in particular brain sections, for example, in the front and temporary areas. Acetylcholine is the most important CNS and peripheral autonomic and somatic systems neurotransmitter [1-2].

\section{About Sesbania grandiflora}

Sesbania grandiflora is known as the agate or the scarlet wisteria tree. This little tree is believed to have been founded either in India or South East Asia and mainly flourishes in the world's warm, humid tropical climates. Native to Asian countries such as India, Malaysia, Indonesia, and the Philippines usually grow among rice paddies along roads and vegetable gardens on the decks. Sesbania grandiflora revealed Sesbania grandiflora acetone and ethanol extract for antioxidant activity with an antioxidant test, total phenolic content, reduced energy efficiency, and inhibited lipid oxidation in the emulsion of the linoleic acid. Semwal et al. demonstrated substantial neuroprotective benefits in celecoxib-treated mice by altering the cholinergic system, blocking oxidative stress, and inhibiting the enzyme AchE. Most species of sesbania are soft, semi- or slightly woody, 1-4 m tall, constantly attaching nitrogen to trees. Sesbania grandiflora bears wide red and white flowers, measuring $10 \mathrm{~cm}$ [3-4].

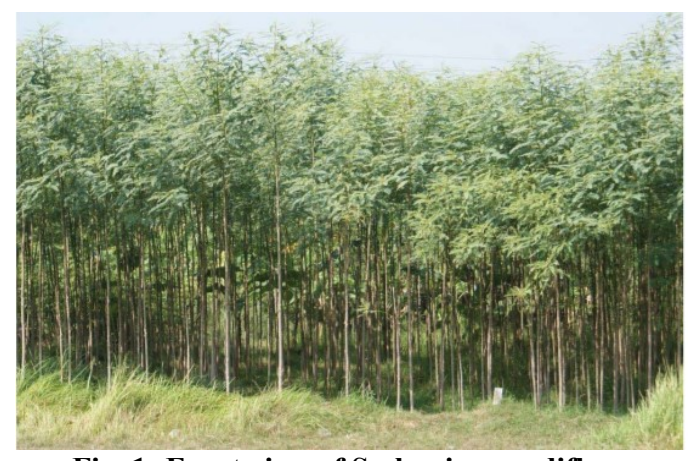

Fig. 1: Front view of Sesbania grandiflora

The plant has a fantastic feature, especially for the first 3 or 4 years after planting, is its rapid growth rate. Plantations in Australia 
and India have reached $8 \mathrm{~m}$ in less than three years. Sesbania is cultivated in the summer months as a cover crop and green manure. The addition of organic materials to the desert soils occurs in developing Sesbania during the micro-organism decomposition of organic materials. Compounds that are decomposition resistant, such as gums, waxes, and resins, help bind soil particles to one another as granules or aggregates. A properly aggregated ground is highly ventilated and has a high rate of water infiltration. Food, firewood, pulp, paper, food, green manure, and landscape decoration are provided in the tree. It also can replant eroded soil and green wastelands in the tropics. The timber is of low quality. Sesbania grandiflora blooms are consumed as plants in Southeast Asia, and the immature pods are eaten together with the leaves. Phytochemical substances are responsible for Sesbania grandiflora antipyretic, antiinflammatory, antioxidant, antibacterial, thrombolytic, and membrane-stabilizing activities. Recent scientific studies showed that Sesbania grandiflora has hepatoprotective solid, cardioprotective, anxiolytic, and anxiolytic activity [5-8].

Sesbania grandiflora leaves have the ability to treat thrombosis, diarrhoea, and inflammatory illnesses, as well as a few essential bacterial infections. Bronchitis, cough, vomiting, sores ulcers, diarrhoea, and dysentery have all been claimed to be treated with the juice of S. grandiflora leaves. Antimicrobial activity has been reported in the flowers. For rheumatic swelling, powdered roots of this plant are combined with water and used externally as a poultice or massage. Nasal catarrah, nyctalopia, and cephalagia have all been treated with the leaves in the past. S. grandiflora has antioxidant, antiuroithiatic, anticonvulsive, anti-arthritic, anti-inflammatory, antihelminthic, antibacterial, and anxiolytic properties, according to studies.

\section{Taxonomy $[9,10]$}

1. Kingdom: Plantae

2. Super divisions: Spermatophyta

3. Class: Magnoliopsida

4. Order: Fables

5. Family: Leguminosae

6. Genus: Sesbania

7. Species: Sesbania grandiflora

\section{Biological description [11, 12]}

Birds appear to pollinate the large-flowered hermaphroditic species. 9 months after planting, S. grandiflora can produce mature pods. The tree has a 20-year life expectancy.

Genetics: The chromosome number of S. grandiflora is $2 \mathrm{n}=24$. 
Reproductive Biology: S. grandiflora seeds are hard-coated and have no dormancy; thus, they will germinate as soon as moisture is available after imbibition. Reproduction is exclusively sexual, like with other Sesbania spp., though rootstocks can be transplanted manually with considerable success. Generalist insect pollinators, such as bees, pollinate flowers, which produce clusters of seed pods on the stems of inflorescences. Some pods dehisce and eject their seeds while still attached to the trees, however the majority of pods detach from the plants while still whole and holding seeds. Seeds are dispersed over long distances by buoyant water-borne pods being transported downstream, with seeds released when the capsules weather and disintegrate.
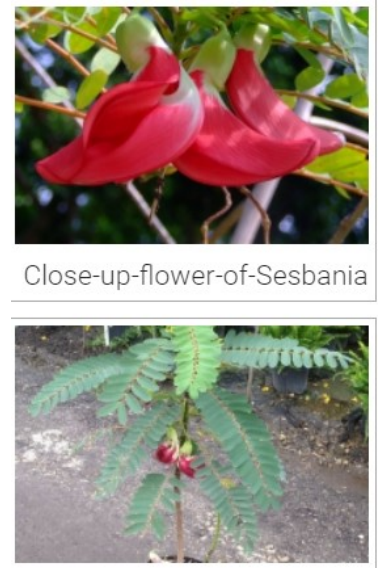

Sesbania-plant

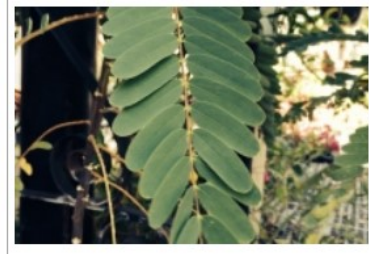

Leaves-of-Sesbania

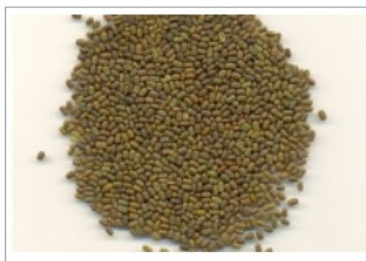

Sesbania-seeds

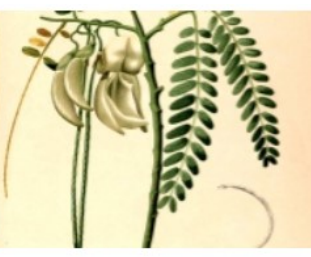

Plant-illustration-of-Sesbania

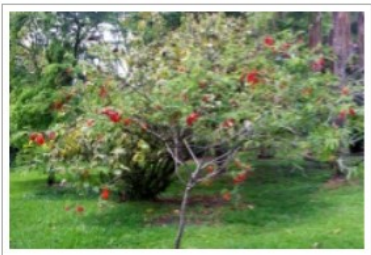

Sesbania-tree

Fig. 2: Sesbania Grandiflora parts

Leaves: The Sesbania grandiflora leaves are bright green, pinnate, about $30 \mathrm{~cm}$ long, and smooth taste.

Flowers: The flowers are 7-9 $\mathrm{cm}$ long, rich rose to red. It tastes acidic, harsh, and addictive.

Bark: The bark of Sesbania grandiflora is light grey in color, corky, and deeply furrowed.

Seed: The grains are oblong, brown, or dark green.
Pod: Slim and straight, pale yellow, $20-60 \mathrm{~cm}$ in length, 15-50 seeds each $8 \mathrm{~mm}$ in size.

\section{Ecology [13]}

Sesbania grandiflora is well suited for hot, wet weather. It is capable of growing in salt and alkaline soil. It can tolerate the circumstance of waterlogging.

\section{Phytochemistry [14, 15,1 6]}

Sesbania Grandiflora phytochemical contains alkaloids, flavonoids, glycosides, tannins, steroids, proteins, carbohydrates, anthraquinones, and saponins. 


\section{Nutritive value of Sesbania grandifolia} $[17,18]$

Sesbania grandiflora leaves contain water, carbohydrate, proteins, lipids, fiber, mineral substances (iron calcium, sodium, potassium), and essential amino acids (thiamine, riboflavin, niacin) (Arginine, histidine, isoleucine, leucine, lysine, and methionine). The roots are made up of isophlavonids, isovestitol, medicarpine and sativan. The active constituents of Agati seeds are leucocyanidin and cyanidation.

Sesbania is a good source of nutrients, vitamins, and minerals, despite its acerbic, bitter, and astringent flavour. 20 grammes of sesbania provide 14.6 milligrammes of vitamin C, 20 milligrammes of vitamin B9, 0.17 milligrammes of iron, 0.2 milligrammes of selenium, 0.017 milligrammes of vitamin B1, and 0.016 milligrammes of vitamin B2. Moreover many Amino acids like $0.004 \mathrm{~g}$ of Tryptophan, $0.011 \mathrm{~g}$ of Threonine, $0.014 \mathrm{~g}$ of
Isoleucine, $0.021 \mathrm{~g}$ of Leucine and $0.013 \mathrm{~g}$ of Lysine are also found in 20 gram of sesbania.

\section{Medicinal plants [19, 20]}

The entire plant and its preparations are utilized in Ayurveda for the treatment of several illnesses and disorders.

Leaves: Fresh leaves are utilized as a migraine ailment, sinusitis, rheumatism, arthritis, gout, and the healing of wounds. Blades are used in the treatment of oral and throat infections as a tonic or paste.

Flowers: Sesbania grandiflora juice is used to alleviate nightbliness, headache, and constipation.

Bark: Bark is utilized to treat diarrhea, pox, malaria, rash, and gonorrhea.

Root: The roots of the Sesbania grandiflora red-flowered variety are used to treat rheumatism.

Seed: The seed of Sesbania grandiflora is anthelmintic.

Table 1: Sources and activities of bioactive compounds with structure

\begin{tabular}{|c|c|c|c|c|c|}
\hline Compounds & Producing strains & $\begin{array}{l}\text { Test organisms/cell } \\
\text { lines }\end{array}$ & $\begin{array}{l}\text { Inhibitory } \\
\text { concentrations }\end{array}$ & $\begin{array}{l}\text { Nature of } \\
\text { bioactivities }\end{array}$ & Ref. \\
\hline Halobacillin (6) & Bacillus sp. CND-914 & $\begin{array}{l}\text { Human HCT-116 } \\
\text { cancer cells }\end{array}$ & $0.98 \mu \mathrm{g} / \mathrm{mL}\left(\mathrm{IC}_{50}\right)$ & Anticancer & [29] \\
\hline Mixirin (11) & Bacillus sp. & $\begin{array}{l}\text { Human HCT-116 } \\
\text { cancer cells }\end{array}$ & $0.68 \mu \mathrm{g} / \mathrm{mL}\left(\mathrm{IC}_{50}\right)$ & Anticancer & [44] \\
\hline Bogorol A (15) & Bacillus sp. & MRSA & $2 \mu \mathrm{g} / \mathrm{mL}(\mathrm{MIC})$ & Antibacterial & {$[45]$} \\
\hline Loloatin B (18) & Bacillus sp. & MRSA, VRE & $1-2 \mu \mathrm{g} / \mathrm{mL}$ (MIC) & Antibacterial & {$[46]$} \\
\hline $\begin{array}{l}\text { Bacillistatins } 1 \text { (19) } \\
\text { and } 2(\mathbf{2 0})\end{array}$ & B. silvestris & $\begin{array}{l}\text { Human cancer } \\
\text { cell line }\end{array}$ & $10^{-4}-10^{-5} \mu \mathrm{g} / \mathrm{mL}\left(\mathrm{GI}_{50}\right)$ & Anticancer & [30] \\
\hline
\end{tabular}


Table-2 Concentration of bioactive compounds in Sesbania calyces

\begin{tabular}{|c|c|c|c|c|}
\hline & Properties & Milk & $\begin{array}{l}\text { Roselle calyces } \\
\text { extract (RE) }\end{array}$ & $\begin{array}{c}\text { Cinnamon extract } \\
\text { (CE) } \\
\end{array}$ \\
\hline & $\overline{\mathrm{pH}}$ & 6.3 & 2.90 & 6.5 \\
\hline & Moisture $\%$ & 86.6 & 99.5 & 93 \\
\hline & T.S $\%$ & 13.3 & 7 & 0.5 \\
\hline & Acidity \% & 0.19 & 0.7 & 0.014 \\
\hline & Ash $\%$ & 0.7 & nd & nd \\
\hline & Fat $\%$ & 5 & nd & nd \\
\hline \multicolumn{5}{|c|}{ Table 3- Pharm Activity, Plant parts and Extract of Bioactive compound } \\
\hline Class & Compounds & Plant Sources & \multicolumn{2}{|c|}{ Mechanism of Actions } \\
\hline \multirow[t]{2}{*}{ Flavone } & Apigenin & $\begin{array}{l}\text { Parsley } \\
\text { Celery } \\
\text { Rosemary } \\
\text { Oregano } \\
\text { Thyme } \\
\text { Basil } \\
\text { Coriander } \\
\text { Chamomile } \\
\text { Cloves }\end{array}$ & \multicolumn{2}{|c|}{$\begin{array}{l}\text { 1. Activation of ERK } 1 / 2 \\
\text { 2. Attenuates the production of pro-inflammatory cytokines } \\
\text { such as } I L-6, I L-1 \beta \text {, and TNF- } \alpha\end{array}$} \\
\hline & Diosmin & $\begin{array}{l}\text { Lemon } \\
\text { Orange } \\
\text { Buddha fingers }\end{array}$ & $\begin{array}{l}\text { 1. Deactivation of NF-1 } \\
\text { 2. Suppression of mon } \\
\text { (MCP-1), tumor necros } \\
\text { (IL- } 1 \beta \text { and } 6 \text { ) }\end{array}$ & $\begin{array}{l}-\mathrm{kB} \text { targets } \\
\text { locyte chemoattractant protein-1 } \\
\text { sis factor (TNF- } \alpha \text { ), and interleukins }\end{array}$ \\
\hline \multirow{3}{*}{ Flavonol } & Quercetin & $\begin{array}{c}\text { Capers } \\
\text { Onions } \\
\text { Cranberries } \\
\text { Blueberrie } \\
\text { Chokeberris }\end{array}$ & \multicolumn{2}{|c|}{$\begin{array}{l}\text { 1. Inhibition of NF- } \mathrm{kB} \text { system } \\
\text { 2. Reduction in serum level of both TNF- } \alpha \text { and CRP }\end{array}$} \\
\hline & Kaempferol & $\begin{array}{c}\text { Tomatoes } \\
\text { Green Tea } \\
\text { Potatoes } \\
\text { Broccoli } \\
\text { Brussels } \\
\text { Sprouts } \\
\text { Squash } \\
\end{array}$ & \multicolumn{2}{|c|}{$\begin{array}{l}\text { 1. AMPK activation } \\
\text { 2. Decrease the fasting blood glucose, and improved } \\
\text { insulin resistance }\end{array}$} \\
\hline & Eriodictyol & $\begin{array}{l}\text { Lemons } \\
\text { Mountain balm }\end{array}$ & \multicolumn{2}{|c|}{$\begin{array}{l}\text { 1. Suppress the activation of NF-kB system } \\
\text { 2. Reduce TNF- } \alpha \text {, intercellular adhesion molecule } 1 \\
\text { (ICAM-1), vascular endothelial growth factor (VEGF), } \\
\text { and endothelial NOS (eNOS) }\end{array}$} \\
\hline
\end{tabular}

\section{Applications of Sesbania grandiflora}

Food: S. grandiflora's leaves, seeds, pods, and flowers are all edible. Flowers are the most popular component, and white flowers are chosen above red flowers. Unopened white flowers are a common food in the Philippines, where they are boiled or cooked in soups and stews after the stamen and calyx have been removed. Thailand eats the uncooked flowers as a salad. Young leaves are consumed as well, usually finely chopped and boiled, sautéed, or fried. String beans are made from tender pods.

Fodder: Leaves and pods are prized for their nutritional content. Within four months of planting, the tree yields fodder leaves. Every 
$100 \mathrm{~g}$ of leaves contains $36 \%$ crude protein (dry weight) and $9600 \mathrm{IU}$ vitamin A. The tree is cut when it is $90-120 \mathrm{~cm}$ tall $(1.8 \mathrm{~kg})$ for fodder production and fed to animals on a rice straw diet. Growth increases were comparable to those obtained by giving prepared meals under this regime. The most efficient way to give fodder to ruminants is to supplement their diet with it up to $15-30 \%$ of the overall diet. S. grandiflora should not be fed to animals alone because of its high protein content; instead, it should be supplemented with a roughage that is low in protein but high in calories, such as rice or maize straw. Supplementing low-quality feed components with S. grandiflora fodder can increase intake.

Fuel: The wood is light and not well rated as a fuel because it produces a lot of smoke when burned. With a weight of only 500 $\mathrm{kg} / \mathrm{square} \mathrm{m}$, it burns quickly and produces little heat. However, because of its rapid growth and availability within a year of planting, it is a popular fuelwood in the area. Because wood deteriorates in storage and becomes corky, dusty, and unfit for burning, it should be well dried. It has a calorific value of $17.91 \mathrm{MJ} / \mathrm{kg}$, a high ash content of $6 \%$, and a low carbon percentage (11.7 percent).
Fibre: S. grandiflora is capable of producing much more cellulose raw material per unit area than most other pulp woods, even with a very short rotation of 3-4 years. Even trees as young as 3-4 years old can be pulped without debarking and used as cheap printing, writing, magazine, and newspaper paper thanks to chemical pulping. The fibres are quite short. To produce good strength, fibre can be combined with long-fibred bamboo pulp in appropriate amounts. On a three-year rotation, roughly $41 \mathrm{t} / \mathrm{ha}$ of pulp can be harvested per year.

Timber: As wood ages, its density rises, and timber from 5- to 8-year-old trees can be used in house construction or as craft wood. The trunk has been utilized for poles, but due to rot and insect infestation, it may not live long. Floating fishing nets are made of this light wood.

Resin or gum: There is a production of bark exudate and seed endosperm gums. The transparent gum from the bark is used as a replacement for gum arabic in meals and adhesives. Tannins are produced by the bark.

Medicine: Sprains and bruises of all kinds are treated with crushed leaves. The leaves are used to make a tea that has antibacterial, anthelmintic, antitumor, and contraceptive qualities. The bark is used as a tonic and antipyretic, as well as a treatment for 
gastritis, colic, diarrhoea, and dysentery. To treat fever and diabetes, a bark decoction is administered orally. The application of floral juice to the eyes is supposed to improve vision. The leaves are also medicinal, and have been claimed to help cattle with night blindness. All plant parts are said to cure night blindness in India. The root is a wellknown malaria treatment.

Leaves and Flowers: Poultices are made from leaves and flowers. The astringency of the tree is what gives it its therapeutic properties, so it's used to treat inflammation, venom and other toxins, bacterial infections, and tumors. Poultices made from root fluids are used to treat rheumatism, swellings, bruises, and itching, while leaves are used to treat rheumatism, swellings, bruises, and itching. Internally, decoctions are used to treat systemic illnesses. Root resin is given orally with honey for phlegm, while root juices are used as an expectorant. Taking a floral decoction relieves sinus congestion.

\section{Dementia:}

In the International Categorisation of Disease (ICD 10, WHO 1992), Dementia is defined as a 'brain syndrome, usually chronic or progressive in nature, due to which many higher cortical functions such as memory, thinking, orientation, understanding, calculation, learning ability, language, and judgment are obstructed.' Dementia comprises a variety of neurodegenerative disorders that cause various difficulties in the functioning of the brain. Dementia is linked to several conditions such as brain blood flow abnormalities, mitochondrial malfunction, and oxidative damage[21]. It is a clinical syndrome, with a steady reduction in mental and cognitive skills, making an individual insufficient to operate independently due to significant memory loss. AIDS that causes indirect damage to the brain by immune-activated macrophages or systemic infections typically lead to Dementia and participates in energy management dysregulation. Some environmental variables, such as chemicals in substances of abuse and air pollution, can potentially cause brain degeneration and Dementia[22]. Dementia is also related to different gene polymorphisms and genetic abnormalities. Dementia is mainly the following:

\section{Types of Dementia:}

Parkinson's disease with Dementia (PD):

Reduced cortical tissue size has been recognized as one of the critical causes of PD and subcortical lesions. It is a sort of Dementia that happens at a later stage of the disease of Parkinson's. This Dementia has increasing dysexecutive syndrome, delaying 
thinking and impairment of acquired information by adding cognitive problems and other psychotic symptoms. There were frequently visual hallucinations featuring distinct, colorful, and rarely fragmented representations of family and friends. Dementia treatment comprised synthetic medications, which relieved symptoms such as donepezil cognition and hallucination, therefore offering just a symptomatic alleviation and did not cure the fundamental cause of disease. Rivastigmine has also been utilized, a dual inhibitor of cholinesterase, butyrylcholinesterase (BuChE), and acetylcholinesterase (AChE). Rivastigmine effectively managed the extrapyramidal symptoms [23].

\section{Lewy body dementia (LBD)}

Lewy bodies are bodies of different forms such as round, triangular and irregular. They were found to be present in truncated forms next to the nucleus. They have a dense inner center and an outside section of neurofilament proteins such as ubicitines, $\alpha$ synuclein, and related enzymes that are abnormally condensed and phosphorylated. In LBD patients, visual hallucinations, olfactory and auditory disorders were regularly detected. These hallucinations led to various emotional conditions such as fear, fun, wrath, etc. Patients also reported hypophonic speech, stuffy posture, and frequent movement-therapy comprised of synthetic medicines such as clozapine, chlormethiazole, and lorazepam. Neuroleptics were also employed, such as thioridazine and sulpiride [24].

\section{Vascular Dementia (VaD)}

It is one of the most common dementia types involving cognitive impairment, caused by a vascular disorder such as a cardiac stroke, atherosclerotic disease, or cardiac arrest that leads to multiple cerebral tissue injuries such as hemorrhage infarction, hippocampal sclerosis, white matter lesions. These modifications lead to Dementia in a way. The signs of this condition include motor slowness, depression, low motivational energy, anxiety, aberrant thoughts, and bodily irregularities. Cerebrovascular lesions can additionally lead to corticospinal and extrapyramidal side-effects such as weakness and slower muscle movement, which contribute in a sense to a delay in behavior and decision-making. Donepezil was used for treatment, which improved cognition in patients. However, a variety of adverse effects have been reported. Rivastigmine has shown significant progress in management functioning, linguistic fluidity, and behavioral tendencies. Memantine showed a 
minor impact on cognition improvement but had fewer adverse effects in patients [25].

Huntington's disease with Dementia (HD)

Huntington's disease is a hereditary condition with Huntington gene mutations that can lead to Dementia. Disease-related symptoms are a combination of three sorts of impairments:

Movement disorders: These are voluntary and unintentional illnesses. These are constant and uneven jerky motions: unnatural eye movements, dysphagia, stiffness, and posture abnormalities.

Cognitive disorders: Aphasia, agnosia, mental speed deficiencies, and flexibility are frequent. Memories and incidents from the past are a massive problem in patients. Visuospatial activity and judicial flaws have also been observed to occur.

Psychotic disorders: Depression, irritability, and apathy have been noted most frequently. Prominent symptoms include sensations of evaluability, self-denial, changes in sleep patterns, hunger change, anxiety, energy loss, and desperation.

Synthetic medications such as amantadine, levetiracetam, and tetrabenazine are incorporated in the treatment. CoenzymeQ10, creatine, and minocycline were also used in several clinical trials. 11 Several inhibitors of selective serotonin reuptake have also been tried and are thought to help
HD patients. Mood stabilizers such as carbamazepine and valproate were designed to contribute to emotional stability and momentum. Psychosis-related symptoms were supposed to benefit antipsychotics. It has been observed that Donepezil, Rivastigmine, and Memantine have dubious advantages in clinical trials [26, 27].

\section{Frontotemporal Dementia (FTD)}

It is a distinct form of Dementia in the front and temporal lobes with progressive atrophy. A physicist, Arnold Pick, also calls for pick's disease[28]. Phosphorylated tau protein, transactive responder DNA-binding protein43 (TDP-43), and fused into sarcoma (FUS) protein are three essential pathogenic proteins involved in developing FTD. There are two vivid forms of FTD:

1. Comportemental variation FTD: Includes changes in personality, disinhibition, and apathy. Reduced inhibition typically leads to poor financial choices, which can lead to financial disasters. Patients are losing their sympathy and empathy with family and friends. Reduction in social responsibility to people's emotional and other needs. Binge eating, increasing sweets or alcohol consumption, and gaining weight are different characteristics[29].

2. Progressive Aphasia: Language prediction defects, object naming, grammar, or word 
comprehension during conversation are apparent.

Motor symptoms are hyperreflexia, spasticity, weakness, atrophy of muscle, and dysphagia. Many synthetic medicines have been utilized. Selective serotonin reuptake drugs like Fluoxetine, Fluvoxamine, Sertraline, or Paroxetine have generally facilitated neuropsychiatric diseases. Antipsychotics such as olanzapine, risperidone, and aripiprazole demonstrated improved cognitive capacities, delusions, restlessness, neuropsychiatric symptoms, and behavior overall. Cholinergic medicines such as rivastigmine, donepezil, and selegiline have demonstrated improved conduct and cognition. However, these synthetic medicines can simply relieve the symptoms rather than treat the fundamental cause [30,31].

\section{Creutzfeldt - Jakob dementia (CJD)}

It's one of the rare dementia types that can be family, sporadic or iatrogenic. The whole event in the development of aberrant prion protein. It is assumed that a faulty prion protein functions as a template for host prion protein to inappropriately plug into a pathogenic shape that produces this type of Dementia. This is an autocatalytic process. The synthetic medications studied, including quinacrine, which decreased and cyclically amplified prion proteins, were ineffective. Flupirtine has been discovered to be neuroprotective by proto-oncogenic BCL-2 overexpression and by normalizing glutathione levels. The cognition of CJD patients was significantly improved. It was noted that pentosan polysulfate had eradicated the aberrant prion protein strain in the mice population, although it had not yet been tested for human efficacy. However, these synthetic medications could provide symptomatic relief only, and this form of Dementia stays untreated [32].

\section{Alzheimer's Dementia (AD):}

$\mathrm{AD}$ is characterized by loss of presynaptic cholinergic neurons, leading to cortical cholinergic deficiency and, therefore, Dementia. The characteristic of this dementia type is the deposition of amyloid ß-protein (A $\beta$ complex) in cortical extracellular plaques and the creation, composed of phosphorylated tau protein, of neurofibrillary tangles. The hippocampus, cortex, and basal nucleus events lead to cholinergic, serotonergic, and noradrenergic impairments. Symptoms of this kind include sleep difficulties, disorientation, confusion, hallucination, aggression, paranoia, apathy, aphasia, sadness, and urine incontinence. Rigidity, tremor, late dyskinesia, snubbing, and grab reflection, the extrapyramidal 
symptoms detected were Babinski reflexes. Many synthetic medicines have been used for the treatment of AD. Tacrine, donepezil, and rivastigmine were mainly employed as cholinesterase inhibitors. Xanomeline and Milameline were also investigated for their effectiveness in symptomatic alleviation by muscarinic cholinergic agonists. Most of these medications could only address the cognitive deficiencies reported in the tests. For most types of Dementia, FDA-approved medications include Rivastigmine, Donepezil, Memantine, and Galantamine. Other synthetic drugs merely provide symptomatic alleviation for demented people so that additional medicines that may potentially treat Dementia are desperately needed. In this respect, medicinal plants can aid. Medicinal plants have a vast spectrum of phytoconstituents that are active in several ways. These botanicals offer a wide variety of benefits both from progression and symptoms linked with various forms of Dementia. The dementia medicinal herbs demonstrate multiple processes, including impacts of $\beta$-Amyloid plaque formation regulation, acetylcholinesterase, acetyl and $\beta$ secretase, NMDA receptors, glutathione levels, and brain blood circulation. Many medicinal plants have been utilized for dementia trials, and most of them have demonstrated potential biological activity [33].

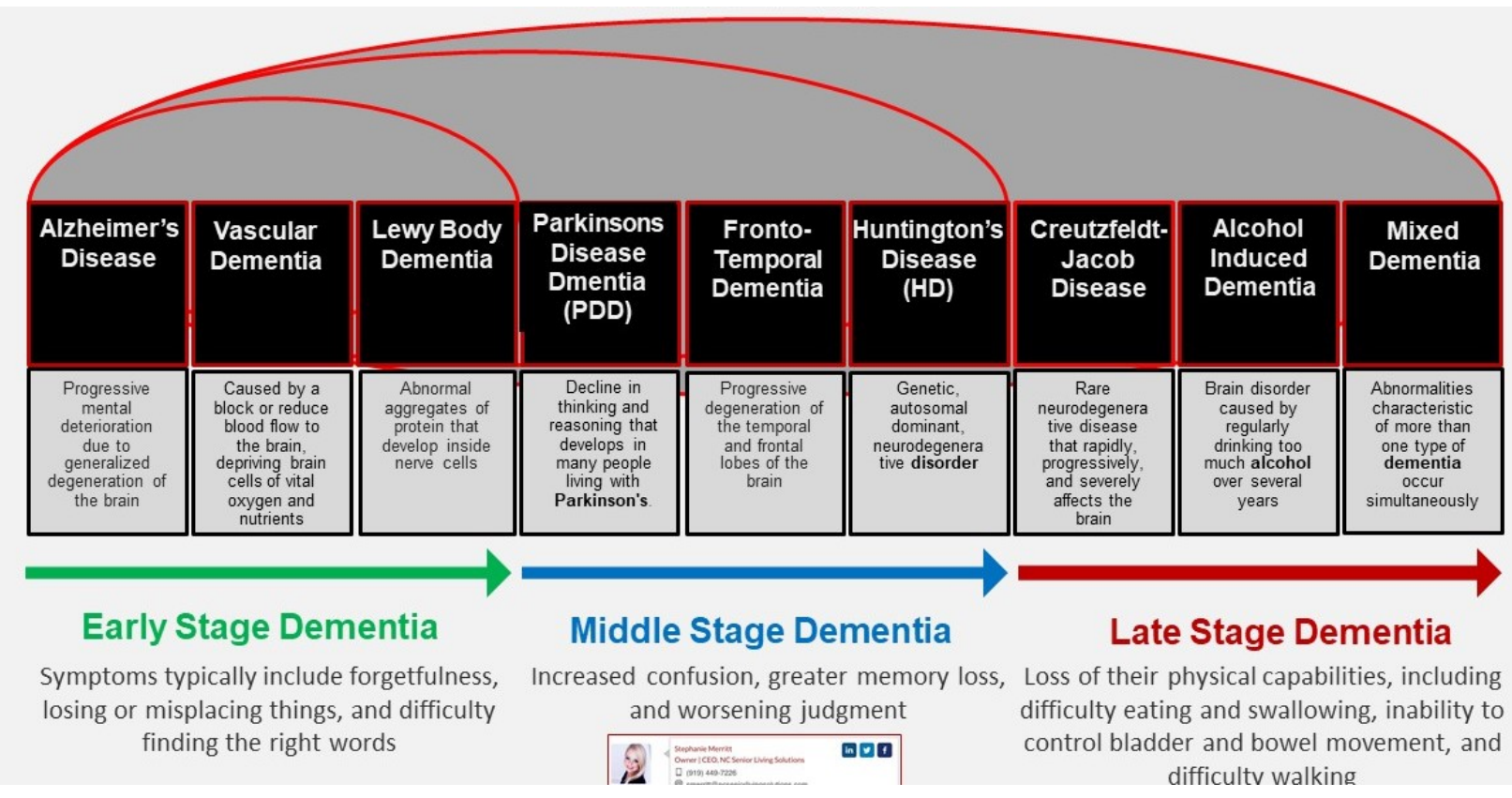

Fig. 3: Different types of Dementia 
Involved in risk factors in the precipitation of Dementia:

Cerebral Ischemia: It is a condition in which oxygen and glucose are reduced to the brain tissue. Pathophysiological processes result in energy deficiency leading to depolarization of the neuronal and activation of glutamate receptors, affecting ionic gradients $\mathrm{Na}^{+}, \mathrm{Ca}^{++}, \mathrm{Cl}^{-}$and $\mathrm{K}^{+}$. As glutamate accumulates in the extracellular region, 54 peri-infarct depolarization occurs. Then cells increase when the water changes with the subsequent cerebral edema. With the growth of $\mathrm{Ca}^{++}$intracellular, numerous enzyme systems, like lipases, proteases, and endonucleases, are elevated. As a result, a variety of metabolic pathways produce free $\mathrm{O}_{2}$ radicals [34]. Free radicals also create inflammatory mediators such as platelet and endothelium selectin, multiple modules, platelet-activating factor, tumor necrosis factor, and interleukins. Mitochondrial failure affects the neuronal calcium homeostasis necessary to control normal neuronal function[35]. Higher intracellular calcium levels in the mitochondrial material accelerate the opening of mitochondrial transition pored, facilitating the formation of reactive oxygen species (ROS).

Hypertension: The risk factor in multiple disorders, including DA, stroke, atherosclerotic Atherosclerosis, myocardial infarction, and cardiovascular diseases, is hypertension, presently defined as systemic blood pressure (SBP) above $140 \mathrm{~mm} \mathrm{Hg}$, and the diastolic blood pressure (DBP) above 90 $\mathrm{mm} \mathrm{Hg}$. Hypertension is estimated to afflict $25 \%$ of the population, with a frequency of $50 \%$ over the age of 70 . But median hypertension (around 30 years old) is mainly associated with an increased likelihood of developing $\mathrm{AD}$ and $\mathrm{VaD}$. In contrast, high blood pressure does not seem to be linked to the same risk late in life. The medium or late in the life of hypertension or elevated blood pressure significantly impacts developing cognitive impairment. Hypertension causes cavities or cortical infarction disorders and leukoaraiosis, ultimately causing cognitive reduction. The effect of hypertension on brain health can increase $A \beta$ production and lead to neural dysfunction, synapse, neuronal death, and Dementia. DBP hypotension at 70 $\mathrm{mm}$ Hg. Hypotension. While high blood pressure is a significant risk factor for $\mathrm{AD}$ and $\mathrm{VaD}$, decreased blood pressure in old age may have adverse cognitive effects. The artery pressure, such as developing $A \beta$ plastics, might be reduced by pathological alterations, which could lead to hypoxic synergy changes with existing pathologies 
that could aggravate the level of Dementia [36].

Hypercholesterolemia: High cholesterol is also a significant risk factor for the induction of cognitive vascular impairment. Hypercholesteremia leads to activation of the $\mathrm{NF}-\mu \mathrm{B}$ pathway. Its overall involvement in inflammation and immunological responses, regulating cell division and death, is well known. I5-0B kinase phosphorylation of I5$\mathrm{OB}$ is one of the critical pathways to NF- $\alpha$ activation (IKK). i5-0b kinase (IKK) affects two catalytic subunits (IKK- $\alpha$ and IKK- $\beta$ ) and one regulatory subunit (IKK- $\beta$ ). In inflammatory induction, the NF- $\beta$ family of transcription factors plays a crucial role. Classical and unconventional NF-TB nuclear translocation control mechanisms are involved. Classical NF- $\mu \mathrm{B}$ activation typically provides a quick and transient response to varied stimuli with the main effector of RelA/p50. The NF-SB pathway is a retarded response to a limited range of incentives that makes the DNA binding on the RelB/p52 complexes. A main inflammatory event, encompassing Huntington, Parkinson's, Stroke, and AD, has been a common feature of various neurodegenerative diseases. Cholesterol also plays a critical role in regulating the enzyme activity involved in the creation of $A \beta$ protein and APP. The hydrophobic lipid bilayer breaks APP, catalyzing the migration of $\alpha$-secretase enzymes. High levels of cholesterol change $\alpha$-secretase activity and contribute to decreased soluble APP levels and increased neurotoxic $A ß$ proteins [37].

Diabetes: Diabetes mellitus (DM) is a growing global condition. DM is metabolism in more than $10 \%$ of the age group associated with mental awareness and flexibility changes. Type $1 \mathrm{DM}$ is characterized by a deficit in pancreatic $\beta$ cell insulin production. Type $2 \mathrm{DM}$ is marked by resistance to insulin. Hyperglycemia has detrimental effects on neurons, leading to functional and cellular brain impairment through oxidative stress and the development of glycemic finished products. Advanced glycolic end products include sugar-derived molecules formed through non-enzymatic interactions between the sugar reduction and free amino groups of proteins, nuclear acids, and lipids. They are typically generated within the body, but glucose availability in diabetes significantly increases their development. The development of AGE promotes incorrect interaction with other matrix proteins and the integrins of modified extracellular matrix proteins resulting in decreased flexibility of the vascular system [38]. 
Furthermore, AGE-modified plasma proteins are ligands that connect to AGE receptors in endothelial cells. Such interaction of the AGE receptor stimulates the activation of the transcription factor known as NFčB in numerous neurodegenerative diseases. Alterations in mitochondrial dynamics and mitochondrial failure lead to insulin, obesity, and diabetes resistance, such as pancreas, liver, muscle skeleton, and white adipose. Mitochondrial dynamics are crucial for the function, survival, and development of the neuron in brain physiology.

Oxidative stress: Oxidative stress is a state in which oxidation overcomes the antioxidant mechanisms of the body. Oxidative stress is damaging because oxygen-free radicals destroy biological components such as lipids, proteins, and DNA. Specific biological processes such as apoptosis, viral growth, and inflammatory response are associated with oxidative stress. Several gene transcription factors, such as the nuclear factor B (NF-B) and the activator protein1 (AP-1), are known by their cyclic oxidation and reduction as oxidative stress biomarkers. Low free radicals are crucial in preserving normal physiological activities, whereas high amounts result in detrimental effects. Antioxidants offer their electron to stabilize the free radicals and to prevent them.
Dementia is characterized by oxidative stress, indicated by increased protein oxidation, lipid peroxidation, decreased polyunsaturated fatty acids (PUFAs), and reactive oxygen species (ROS). ROS has been engaged for a long time in dementia etiology and is linked with inflammation, damage, and poor blood flow in the brain, which leads to cell injury and death. Mitochondria are considered to be the essential manufacturing location for ROS [39].

Superoxide anion $\left(\mathrm{O}_{2} \cdot-\right)$ is the most abundant free oxygen radical in mitochondrial enzymes caused by the poor transport of electrons. The leakage of electrons in molecular oxygen from complexes I and III produces a superoxide anion $\left(\mathrm{O}_{2} \cdot-\right), \mathrm{O}_{2} \cdot-$ the generation rate depends on the number of electrons available in the mitochondrial respiratory chain. The superoxide anion formation $\left(\mathrm{O}_{2}^{\bullet-}\right)$ has been increased under hyperoxia, hyperglycemia, and diabetes. However, with hypoxia, the superoxide anions $\left(\mathrm{O}_{2} \cdot-\right)$ accumulate because the last electron receiver $\left(\mathrm{O}_{2}\right)$ lacks complex IV. Dismutase Anion Superoxide Enzymes $\left(\mathrm{O}_{2} \bullet-\right)$ detoxify anion by converting it into hydrogen peroxide ( $\mathrm{H} 2 \mathrm{O} 2)$. $\mathrm{H} 2 \mathrm{O} 2$ is not free radical and less reactive than $\mathrm{O}_{2} \bullet-$ less damaging [40]. 
Tobacco smoking: There are around 1.3 billion tobacco smokers worldwide, and this quantity is projected to be 1.7 billion by 2025. Long-term cigarette smoking can contribute to the development of individual CVS diseases. Chronic exposure to smoke can lead to mitochondrial malfunction and progressively oxidative stress in ROS generation. Regular smoking in the mitochondrial respiratory chain (MRC) has harmful effects on the complex IV and III activities which are viewed as the pathogenic mechanism behind tobacco use. Mitochondrial neuronal dysfunction can cause oxidative stress and Dementia. Smoking generates several unfavorable effects by vascular Atherosclerosis and thrombosis, which increase the chance of cognitive decline. Firstly, cigarette exposure has been discovered to induce Atherosclerosis, which leads to increased ischemic strokes and, therefore, Dementia. Secondly, it was revealed that $\mathrm{A} \beta$ neurotoxic effects regulate, offer substantial neuroprotective advantages, and resist Dementia. Cigarette nicotine causes nicotine acetylcholine receptors to control and activate receptors, which protect against $A \beta$ cytotoxicity [41].

Alcohol consumption: Drinking alcohol is one of the health issues of the world. Alcohol consumption has both beneficial and detrimental impacts on the disease's pathogenesis. Various drinking habits affect our body physiology many times, while moderate alcohol damages our health (under specific situations). The effects of heavy alcohol and alcohol use are memory detrimental. However, the risk of Dementia is more severe for people who have discontinued medium-life alcohol or have consumed more than 14 units a week, according to a new study. Drinking is neurotoxic and chronic intakes of long-term drinking can lead to neurodegenerative conditions such as brain degeneration and alcohol dementia. The neurotoxicity processes generated by alcohol are still poorly understood. High AGE-albuminactivated microglial cells can play a vital role in promoting alcoholic neurodegeneration according to one concept. Ethanol can hinder the formation of ROS and cell defense systems. These detrimental effects of ethanol can be seen in the liver, the primary source of ethanol metabolism in the body [42].

Atherosclerosis: Atherosclerosis is due to a prolonged inflammation that gradually limits blood flow via the coronary artery, which in the end causes multiple cerebrovascular and cardiovascular disorders by the accumulation of cholesterol macrophages, smooth muscle 
cells (SMCs). Large and medium-sized arteries are known to be affected by Atherosclerosis. The Willis circle, Atherosclerosis, is part of the brain's cerebral circulation. With the Willis circle, the blood arteries are more prone to Atherosclerosis and increase their severity with age. Atherosclerotic plates may disintegrate, and thrombosis may ensue. The thrombus could occultation of the blood artery, causing an embolism. Embolism commonly occurs in the extracerebral portions of the vertebral arteries. An atherosclerotic aneurysm affects the wall of the brain, typically resulting in rupture and blood. Vascular dysfunction in the brain hence contributes to stroke and vascular Dementia. They are also connected with CVS pathogenesis caused by mitochondrial dysfunctions, such as excessive blood pressure, cardiac hypertrophy, Atherosclerosis, etc. Excessive synthesis of mitochondrial-reactive oxygen increases the loss of beta cells in the pancreas and increases LDL oxidation and atherosclerosis-promoting factor endothelial cell dysfunction. Mitochondrial dynamic perturbations can encourage apoptosis and accelerate plaque rupture. Subclinical incidences of plaque rupture can advance to hemodynamically severe atherosclerotic lesions. Flow-limiting plaque fracture can result in myocardial infarction and stroke [43].

Stroke: In post-stroke people, cognitive impairment and Dementia are prevalent. Brain and dementia illness are extremely tightly connected. Vascular Dementia generally starts after an ischemic stroke. However, the leading causes of cognitive impairment are still unknown following an injury. Those at high risk of stroke may be at increased risk of cognitive impairment and dementia after stroke. Stroke is the most common risk factor for $\mathrm{VaD}$, including the rise in $\beta$-amyloid and tau protein syntheses [44]. The expression of amyloid precursor protein (APP) upregulates $\beta$ amyloid Oligomer extracellular spaces in the brain after the ischemic episode. It promotes the amyloid precursor protein astrocyte production. The interaction between Amyloid and components such as apolipoproteins, green lines, tau protéins, alpha-synuclein, and inflammatory factors results in ischemic brain degeneration involving degradation of white matter and cell death. Except for necrotic cell mortality, neuronal death (including apoptosis) starts after several hours and lasts for several days.

Blood-Brain Barrier Dysfunction: The blood-brain barrier disturbance is another likely hypothesis for cognitive impairment 
etiology. The BBB in all vertebrates is an essential regulator for the neuronal and glial cell habitats and restricts the free spread of substances, leukocytes, and red blood cells in the brain. The barrier is caused by epithelial, highly resistant, tight junctions that join endothelial brain capillary cells into a continuous cell layer that separates blood from the brain. Disruption of close links in endothelial cells between brain and blood can lead to an altered molecular transport, aberrant angiogenesis, regression of the vessel, hypoperfusion of the brain and inflammatory responders, and adverse reaction to neural synaptic plasticity. The microvascular density reduced, fragmentation of the ship increased, the thickening of cellular membrane rose, the vessel width increased, and endothelial mitochondria decreased. Two central recipients are responsible for amyloids input and output throughout the BBB [45].

Hyperhomocysteinemia: Homocysteine is one of the essential indications of neurodegenerative illnesses. Increased homocysteine levels correlate with neurodegenerative disorders, including Alzheimer's disease, vascular dementia, cognitive impairment, or stroke. Serious individuals with hyperhomocysteinemia (HHcy) are more likely to be neurological.
Atherosclerosis, stroke, and Dementia are associated with homocysteine disorder. Homocysteine enables the restoration of an extracellular matrix using redox signals and changes in intracellular calcium dynamic through the activated metalloproteinase-9 (MMP-9) matrix. Calpains are the calciumdependent cysteine proteases that increase oxidative damage in mitochondrial failure. Mitochondrial abnormalities have been reported in hyperhomocysteinemia. Severe hyperhomocysteinemia (HHcy) also indicates inadequacy in vitamin $\mathrm{B}$; $\mathrm{d}$ vitamin $\mathrm{B}$ medication can enhance the clinical results of CLI patients [46].

Heavy metal: Arsenic creates health problems because of its high toxicity and global presence in drinking water and groundwater. Arsenic high-dose is a known neurotoxin having neurodevelopmental and neurocognitive effects. Arsenic exposure was demonstrated to produce morphological and neurochemical hippocampal abnormalities and other neuronal regions associated with memory and forecasted memory and learning losses. Arsenic (As) is a hazardous metalloid abundantly found in the environment and has developed into a global public health problem, including prolonged water exposure. Arsenic is a famous neurotoxic substance contributing to learning and 
memory impairment. The NMDA receptor and signal protein combination play a crucial role in synaptic plasticity, education, and memory. It has been studied as a new expression of the complex NMDA receptor post-synaptic signaling protein to account for arsenic-induced neurotoxicity and memory impairment. Some researchers have also observed that arsenic exposure has caused biogenic amines in the brain (norepinephrine, serotonin, and dopamine), memory, and learning impairment. Some researchers have identified detrimental changes in neural synapses exposed to Arsenic, leading to spatial memory impairment. Very few scientists have established that the $\mathrm{Ca}^{2+} /$ calmodulin-based protein kinase IV, an essential regulator of long-term depression (LTD), induces exposure-related learning and memory impairment. Arsenic has also been identified in the development of brain poisoning to trigger autophagy. But autophagy causes a disturbance in cytoprotective autophagy in a cytoprotective reaction and damages the brain cell/tissue and, after that, the learning and memory [47].

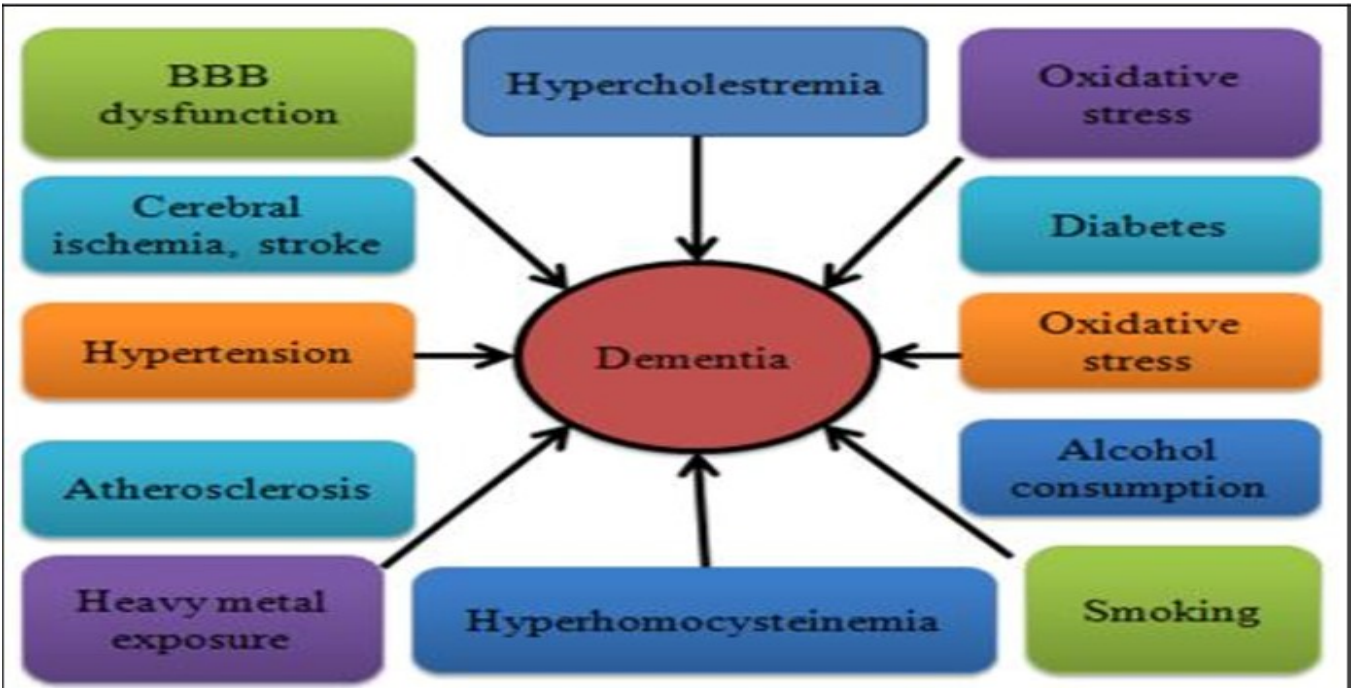

Fig. 4: Different risk factors associated with the Dementia

\section{Traditional uses of Sesbania grandiflora:}

The red-flowered varietal root bark is beneficial in vitiated Vata and arthralgia.

The bark is astringent, refreshing, bitter, tonic, anthelmintic, and feverish. The pounded bark is used for the treatment of scabies externally. Bark juice is beneficial for dyspepsia, diarrhea, and gastralgia.

The leaves are acrid, bitter, sweet, cooling, aperitif, tonic, and diuretic and contain an ingredient resembling a non-poisonous sapphire: nasal catarrh, nyctalopia, and cephalalgia using the leaf juice. Blades are 
known for disinfecting the mouth and throat and are suitable for stomatalgia.

The flowers are chilly, bitter, astringent, cunning, and antipyretic. The juice of the flowers is utilized in intermittent fever for nyctalopia on the eyes. The fruit is sweet, bitter, and astringent, excellent, bitter, tonic, laxative, febrifuge, heal scabies, dyspepsia, diarrhea and gastralgia, nyctalopia anemia, emaciation, and the vitiated tri dosha conditions. The ethanol extract of leaves and blossoms is anti-cancerous, cardioprotective, and antioxidant. The leaf juice has antiurolithic activity; hepatoprotective activity Blooms were evaluated for anxiolytic and anticonvulsant activity, extract of the leaves had wound healing activity, the bark had anti-ulcer training, the leaves, stems and granules and plant roots had antibacterial activity, seed oils and flowers were anthelmintic, the bark had an antiinflammatory and anti-arthritis activity [46, 47].

\section{Some Medicinal plants used in the treatment of Dementia}

Table 4: Medicinal plants, their active constituents, part of the plant used, and mechanism of action $[44,45,47,49]$

\begin{tabular}{|c|c|c|c|c|}
\hline $\begin{array}{c}\text { Common name Botanical } \\
\text { name and Family }\end{array}$ & $\begin{array}{c}\text { Chemical } \\
\text { constituents }\end{array}$ & $\begin{array}{c}\text { Form/ fraction of } \\
\text { the plant }\end{array}$ & $\begin{array}{c}\text { Used against the type of } \\
\text { Dementia }\end{array}$ & Mechanism of action \\
\hline $\begin{array}{c}\text { Turmeric } \\
\text { Curcuma longa } \\
\text { Zingiberaceae }\end{array}$ & $\begin{array}{l}\text { Curcumin, } \\
\text { curcuminoids }\end{array}$ & $\begin{array}{l}\text { Roots and } \\
\text { rhizomes }\end{array}$ & AD, HD, PD, VaD & $\begin{array}{l}\text { Decrease in the formulation of } \\
\text { amyloid plaques and delay in } \\
\text { degradation of neurons. }\end{array}$ \\
\hline $\begin{array}{c}\text { Safron } \\
\text { Crocus sativus Iridaceae }\end{array}$ & $\begin{array}{c}\text { Crocin, safranal, } \\
\text { crocetin }\end{array}$ & Flower & AD & $\begin{array}{l}\text { Inhibition of oxidation induced } \\
\text { formation of toxic amyloid fibrils }\end{array}$ \\
\hline $\begin{array}{c}\text { Ashwagandha Withania } \\
\text { samnifera Solanaceae }\end{array}$ & $\begin{array}{c}\text { Withanolide A, } \\
\text { withanolide IV, } \\
\text { withanolide VI, } \\
\text { sitoindosides VII, X }\end{array}$ & Roots & PD, AD, HD & $\begin{array}{c}\text { Inhibition of AchE and decreased } \\
\text { level of } \beta \text { - amyloid peptide and } \\
\text { glutathione level }\end{array}$ \\
\hline $\begin{array}{c}\text { The tea plant, Tea shrub } \\
\text { Camellia Sinensis } \\
\text { Theaceae } \\
\end{array}$ & $\begin{array}{l}\text { Epigallocatechin-3- } \\
\text { gallate }\end{array}$ & Leaves & Vad & $\begin{array}{c}\text { Elevation of } \alpha \text {-secretase activity } \\
\text { and inhibition of } \beta \text {-secretase } \\
\text { activity }\end{array}$ \\
\hline $\begin{array}{c}\text { Gotu Kola } \\
\text { Centella Asiatica } \\
\text { Apiaceae } \\
\end{array}$ & $\begin{array}{l}\text { Asiaticoside, } \\
\text { centelloside, } \\
\text { brahmoside }\end{array}$ & Flowers & AD, HD & $\begin{array}{l}\text { Inhibition of AChE inhibitor } \\
\text { activity, decrease in the level of } \beta \text { - } \\
\text { amyloid and oxidative stress. }\end{array}$ \\
\hline $\begin{array}{l}\text { Toothed clubmoss Huperzia } \\
\text { serrata Lycopodiaceae }\end{array}$ & $\begin{array}{l}\text { Huperzine A, } \\
\text { huperzine B }\end{array}$ & Moss & VaD, AD & $\begin{array}{l}\text { Inhibition of AChE, anti- } \beta- \\
\text { amyloid peptide fragmentation, } \\
\text { inhibition of oxygen-glucose } \\
\text { deprivation, and NMDA receptor } \\
\text { antagonism }\end{array}$ \\
\hline $\begin{array}{c}\text { Gall nut } \\
\text { Terminalia chebula } \\
\text { Combretaceae }\end{array}$ & $\begin{array}{l}\text { Chebulic acid, gallic } \\
\text { acid, ellagic acid }\end{array}$ & Fruit & AD & $\begin{array}{c}\text { Inhibition of AchE and BuChE } \\
\text { levels }\end{array}$ \\
\hline
\end{tabular}


Therapeutic approaches in the treatment of Dementia:

Nuclear factor Kappa B- receptors antagonists: The kappa-B (NF $\mu-\mathrm{B})$ family transcription factor impacts the induction and resolution of inflammation. $\mathrm{NF} \alpha-\mathrm{B}$, including endothelial dysfunction, is hypothesized to promote cardiovascular disease by proinflammatory, pro-active, and pro-oxidant gene transcription. It was also suggested that NF $\alpha-B$ includes neuronal cell death by amyloid beta-42 and associated memory loss. NF $\mu-b$ is activated in aging-induced Dementia, which results in pro-inflammatory enzyme genes being upregulated. Inhibition of NF-B was discovered to have a beneficial effect in experimental $\mathrm{VaD}$ [50].

\section{NADPH oxidase inhibitor: NADPH} oxidase is a complicated enzyme multisubunit that plays a vital role in creating microbial extracellular and intracellular ROS. It is an electron transport process that produces vast amounts of superoxide through the reduction of molecular oxygen. NADPH oxidase produces reactive oxygen (ROS) species and participates in many physiological functions such as host protection and signal transmission. NADPH is a superoxide enzyme that is stimulated drastically in the $\mathrm{AD}$ brains and involved in several oxidative stress scenarios, including hypertension. The excessive superoxide $(\mathrm{O} 2-)$ radicals in the APP mouse's brains have been shown to result from NADPH oxidase activity, ROS inhibition, and cerebrovascular dysfunction caused by $\mathrm{A} \beta$ and aging of either pharmacological inhibitors or NADPH complex substances. NADPH enzymes impair brain microcirculation endothelium-dependent responses in cerebrovascular cells that can increase susceptibility to cellular malfunction, cell death, and Dementia. The 4'hydroxy-3'methoxyacetophenone (HMAP) inhibitor of NADPH oxidase has considerably averted the malfunction of the STZ in rats with endothelial, cognitive impairment, and metabolic abnormalities [51].

HMG-Co A Reductase inhibitors: Statins are popularly known as HMG-Co A reductase inhibitors and commonly treat cardiovascular diseases. Statins are usually used to lower serum cholesterol levels and hence minimize death from coronary heart disease. Statins are claimed to have been antioxidant and neuroprotective. Statins also improve the learning and memory of animals. Statins have shown numerous approaches to minimize the incidence and memory impairment of ischemic stroke. L-methionine statins were also suggested to have induced $\mathrm{VaD}$ to improve their action. 
Angiotensin II blockers: The local reninangiotensin (RAS) system is a multifunctional brain system. Brain angiotensin II (AT-II) has also been engaged in cognitive decline pathogenesis, and treatment advantages are shown in $\mathrm{AD}$ for angiotensin receptor blockers (ARBs). Lower stroke, stroke severity, occurrence, and development of Dementia were demonstrated to be receptor-1 blockers of AT-II type-1 (ARBs). ARBs protect the brain and cognitive impairment by increasing brain circulation and reducing oxidative stress [50, $51]$.

PPAR $\gamma$ Agonists: Peroxisome Proliferatoractivated receptors (PPARs), which are typically present in three isoforms $(\alpha, \beta / \mu$, and $\mu$ ), are ligand-activated transcription factors. PPAR $-\mu$ is located in the vascular cells, performs an endothelial protective impact. The PPAR- $\mu$ receptors are typical across the central nervous system, and the activation of these receptors prevents neuronal death through oxidative stress reduction and inflammatory processes. Furthermore, PPAR $\mu$ agonists have the possibility of altering several signals/pathways, including MAPK, signal transducer, and transcription activator, amyloid protein degradation precursor, the amyloid protein cleaving enzyme (BACE 1) beta-site and WnT signals. Furthermore, PPAR $-\mu$ has recently been found to be involved in memory and cognitive function improvements in AD.

Androgens: Testosterone is a gonad hormone of sex steroids that affects particular body tissues, including the brain. This hormone increases muscle mass, sexual function and desire, and the risk of osteoporosis beyond reproduction. Testosterone is also known to trigger neurogenesis. This hormone is determined by the morphological and behavioral patterns of the adult throughout crucial critical stages of significant nerve growth (CNS). The neural signals of mitogen-activated protein kinase in the neuroprotective androgen mechanism (MAPK). In cultivated neurons, MAPK was known to activate testosterone and its metabolites, including activation of the extracellular signal-regulated kinase (ERK)-1 and ERK-2.

It is interesting to note that pharmacological elimination of MAPK/ERK signaling provides neuroprotection against betaamyloid damage. DHT sequentially improves p90 kDa S6 kinase (RSK) phosphorylation and $\mathrm{BCl}-2-$ related death-promoters Protein phosphorylation inactivation based on ERK phosphorylation (BAD). Risk prevention of androgen-producing phosphorylation and 
inadequately inhibited androgen neuroprotection. The findings lead to hypertension of blood glycemia, total cholesterol, lipoprotein of low density, proinflammatory cytokines, and an increase in artery wall thickness [52].

\section{Inducible Nitric oxide synthase (iNOS):} Nitric oxide (NO) is essential for regulating homeostatic conditions in cardiovascular, immunological, and neurological systems. NO is the NO Synthase (NOS) enzyme found in 3 neuronal (nNOS) classes; non-inducible (iNOS); (eNOS). Inducible nitric oxide synthase (iNOS) is important for neuroinflammation. It is a key signaling molecule and redox component in the brain.

HDAC (Histone Deacetylase) Inhibitors: The inhibitor of histone deacetylase (HDACis) is an agent in which histone deacetylase (HDAC) is inhibited and which after translation facilitates acetylation of the residual lysine in nuclear and cytoplasmic proteins. The HDAC inhibition has an extensive impact on histone protein acetylation (within chromatin) and improves gene expression associated with ischemic insult protection. Recent research has revealed the neuroprotective function of histone deacetylase (TSA), sodium butyrate (SB), and vorinostat suberanilohydroxamic acid in hydroxyischemia injury (SAHA).
Histone deacetylase inhibitors (HDACs) display neuroprotection by preventing chemokines CXCL10, IL-1 $\beta$, and COX-2 of the blood levels in the ipsilateral hemisphere. Histones and other proteins play a vital role in the homeostasis of protein acetylation and in regulating crucial cellular functions like transcription in histones and other proteins. Histone proteins are critically acetylated and chromatin-associated deacetylated in epigenetic transcription regulation and other processes, including cell neurons. For HDAC inhibition, neuroprotective effects were shown both in-vivo and in vitro models of brain illness.

\section{CONCLUSION:}

Medicinal or ethnomedicinal plants were employed in different ancient cultures, one of which is Sesbania grandiflora. As human food, Ayurveda treats microbiological infections, anemia, laxative, hepatoprotective and cardioprotective agents, urinary rock prevention, therapy, etc. The plant components are used alone or in concert with other medicinal plants as solid therapeutic agents. The presence of plant compounds and phytonutrients contributes to the pharmacology of the plant. Dementia is the loss of cognitive capacity to interfere with social and working tasks. Different symptoms of Dementia include daily 
impairment, (ii) misbehavior, and (iii) cognitive decline. Dementia usually occurs after the age of 65 . It can sometimes emerge before 65 years of age, though, known as the early onset of Dementia. For numerous reasons, many patients are not diagnosed with Dementia until late in the disease but show substantial cognitive deficits. However, mild cognitive impairment (MCI) is thought to be significant in the development of Dementia. Several medications are currently available to treat Dementia.

However, current drugs can provide moderate symptomatic relief but cannot stop the disease from progressing. To avoid the development of Dementia, the mechanism involved in the pathophysiology of underlying disorders must be interfered with. It is essential for the underlying pathogenic pathways to uncover distinct therapeutic strategies to produce novel drugs with disease modification qualities that will provide more competent future therapy alternatives. The article offers a few short reports on the possibly novel treatment drugs, including kappa-B (NF $\beta-\mathrm{B})$ receptor antagonists, NADPH inhibitor oxidase, HMG-Co A reductase inhibitors, angiotensin II blockers, and PPAR $\beta$ androgen agonists, androgen-deacetylase and inducible nitric oxides (iNOS).

\section{REFERENCES:}

[1] www.nhp.gov.in/introduction-andimportance of medicine plants and herbs mtl.

[2] www.shodhaganga.inflibnet.ac.in.

[3] www.dhyansanjirani.org/herbal therapy.asp.

[4] www.FlowersofIndia.net/catalog/slides/A gati.html.

[5] www.ehorticulture.com/tree_plantsseeds/ornamentalplants/Sesbania grandiflora.html.

[6] The indianvegan.blogspot.in/2014/01/all about agathi-sesbania- grandiflora.html.

[7] Nafisa Binte Arfan, Azima Sultana Julie, AK Mohiuddin, et al. Medicinal properties of the sesbania grandiflora leaves. Ibnosina Journal of Medicine and Biomedical Sciences, 2016; 271-277.

[8] www.bimbima.com//ayurveda/medicinaluse of agastya Sesbania grandifloratree/1248.

[9] www.tropicalforages.info/key?forages?M edia/html/Sesbania grandiflora.html.

[10] www.fao.org/ag/agp/agpc/doc/gbase pf000171.html.

[11] www.easyayurveda.com?2015/10?15?a gastya sesbania.

[12] Arun A, Karthikeyan P, Sagadevan P, et al. Phytochemical screening of 
Sesbania grandiflora (Linn), 2014; 1(2): 33-36.

[13] Hasan N Osman H, Mohamed S. Chong WK, Awang $\mathrm{K}$, et al. The chemical components of Sesbania grandiflora root and their antituberculosis activity.

[14] www.Hort.purdue.edu/newcrop/duke energy/Sesbania grandiflora.html.

[15] Tewari D, Stankiewicz AM, Mocan A, Sah AN, Tzvetkov NT, Huminiecki L, Horbanczuk JO and Atanasov AG, Ethnopharmacological Approaches for Dementia Therapy and Significance of Natural Products and Herbal Drugs, Frontiers in Aging Neuroscience, 10, 2018.

[16] Dayalu P and Albin RL, Huntington Disease: Pathogenesis and Treatment. Neurologic Clinics 2015; 33: 101-114.

[17] Bang J, Spina S and Miller BL, Frontotemporal Dementia, The Lancet, 2015;386: 1672-1682.

[18] Manix M, Kalakoti P, Henry M, Thakur J, Menger R, Guthikonda B and Nanda A, Creutzfeldt-Jakob Disease: Updated Diagnostic Criteria, Treatment Algorithm, and the Utility of Brain Biopsy, Journal of Neurosurgery 2015; 39: 1-11.
[19] Schultz BG, Patten DK and Berlau DJ: The role of statins in both cognitive impairment and protection against dementia: a tale of two mechanisms. Tran Neur 2018; 7- 5.

[20] Mukohda M, Stump M, Ketsawatsomkron P, Hu C, Quelle FW and Sigmund CD: Endothelial PPAR- $\gamma$ provides vascular protection from IL$1 \beta$-induced oxidative stress. Am J Physiol Heart Circ Physiol 2016; 310(1): H39-H48.

[21] Warden A, Truitt J, Merriman M, Ponomareva O, Jameson K, Ferguson LB, Mayfield RD and Harris RD: Localization of PPAR isotypes in the adult mouse and human brain. Sci Rep 2016; 6: 27618.

[22] Vigil P, Pablo del Río J, Carrera B, ArÁnguiz FC, Rioseco $\mathrm{H}$ and Cortés ME: Influence of sex steroid hormones on the adolescent brain and behavior: An update. Linacre Q 2016; 83(3): 308-29.

[23] Jaworska J, Ziemka-Nalecz MZ, Sypecka J and Teresa Zalewska T: The potential neuroprotective role of a histone deacetylase inhibitor, sodium butyrate, after neonatal hypoxiaischemia. J Neuroinflam 2017; 14: 34. 
[24] Parbin S, Kar S, Shilpi A, Sengupta D, Deb M, Rath SK, and Kumar Patra SK: Histone Deacetylases: A saga of perturbed acetylation homeostasis in cancer. J Histochem Cytochem 2014; 62(1): 11-33.

[25] Lahera V, de Las Heras N, López-Farré A, Manucha $\mathrm{W}$ and Ferder L: Role of mitochondrial dysfunction in hyper - tension and obesity. Curr Hypertens Rep 2017; 19(2): 11.

[26] Bakthavachalam $P$ and Shanmugam PST: Mitochondrial dysfunction Silent killer in cerebral ischemia $\mathrm{J}$ Neurol Sci 2017; 375: 417-23.

[27] Chang D, Liu J, Bilinski K, Xu L, Steiner GZ, Seto SW and Bensoussan A, Herbal Medicine for the Treatment of Vascular Dementia: An Overview of Scientific Evidence, Evidence-Based Complementary and Alternative Medicine, 2016.

[28] Avneet G, Manish Pal S and Siddhraj SS, A review on herbal Ayurvedic medicinal plants and its association with memory functions, The Journal of Phytopharmacology 2018; 7: 162- 166.

[29] Nishteswar K, Karra R and Joshi H, Role of indigenous herbs in the management of Alzheimer's disease, Ancient Science of Life 2014; 34: 3-7.
[30] Sanka N, Santhipriya N and Nadendla RR, Journal of Drug Delivery and Therapeutics, An updated review on AntiAlzheimer ' s herbal drugs, 2018; 8: $360-372$.

[31] Kumar GP, Anilakumar KR and Naveen S, Phytochemicals having neuroprotective properties from dietary sources and medicinal herbs, Pharmacognosy Journal, 2015; 7: 1-17.

[32] Kaur J, Singh R, Singh G, Kaur H, Kaur J, Kaur M, Singh P and Kaur J, A systematic review on Huperzia serrata, International Journal of Pharmacognosy and Phytochemical Research, 2016; 8: 1250-1255.

[33] Zhu JD, Wang JJ, Zhang XH, Yu Y and Kang ZS, Panax ginseng extract attenuates neuronal injury and cognitive deficits in rats with vascular dementia induced by chronic cerebral hypoperfusion, Neural Regeneration Research, 2018 ; 13: 664-672.

[34] Kyriakoudi A, Ordoudi SA, Medina MR and Tsimidou MZ, Saffron, A Functional Spice, Austin Journal of Nutrition and Food Sciences, 2015; 3: $1-5$.

[35] Dua JS, Prasad DN, Tripathi AC and Gupta R, Role of traditional medicine in neuropsychopharmacology, Asian 
Journal of Pharmaceutical and Clinical

Research 2009; 2: 72-76.

[36] Afshari AR, Sadeghnia $H R$ and Mollazadeh H, A Review on Potential Mechanisms of Terminalia chebula in Alzheimer's Disease, Advances in Pharmacological Sciences 2016.

[37] Farooqui AA, Farooqui T, Madan A, Ong JHJ and Ong WY, Ayurvedic Medicine for the Treatment of Dementia: Mechanistic Aspects, Evidence-Based Complementary and Alternative Medicine 2018.

[38] Choudhary S, Kumar P and Malik J, Plants and phytochemicals for Huntington's disease, Pharmacognosy Reviews, 2013; 7: 81-91.

[39] Dwivedi C, Chandrakar K, Singh V, Tiwari SP, Satapathy T, Kesharwani S, Kumar B and Amit Roy, Indian herbal medicines used for treatment of Dementia: An Overview, 2014;1: 553571.

[40] Manap ASA, Vijayabalan S, Madhavan P, Chia YY, Arya A, Wong EH, Rizwan F, Bindal $\mathrm{U}$ and Koshy S, Bacopa monnieri, a Neuroprotective Lead in Alzheimer Disease: A Review on Its Properties, Mechanisms of Action, and Preclinical and Clinical
Studies, Drug Target Insights, 2019; 13: $1-13$.

[41] Singh AK, Gupta A, Mishra AK, Gupta V, Bansal $\mathrm{P}$ and Kumar S, Medicinal Plant for Curing Alzheimer's Disease, International Journal of Pharmaceutical \& Biological Archives 2016; 1: 108114

[42] Bihaqi S, Rashaan $S$ and Tiwari $M$, Convolvulus pluricaulis as a Cognition Booster: Relevance to Alzheimer's Disease, International Journal of Pharmaceutical Sciences and Drug Research, 2016; $8: 68-74$.

[43] Li CL, Tsuang $\mathrm{YH}$ and Tsai TH, Neuroprotective Effect of Schisandra Chinensis on Methyl-4-Phenyl-1,2,3,6Tetrahydropyridine-Induced

Parkinsonian Syndrome in C57BL/6 Mice, Nutrients, 2019; 11: 1-17.

[44] Singh BKS: Alzheimer's disease: a comprehensive review. International Journal of Pharmaceutical Sciences and Research 2019; 10 (3): 993-1000.

[45] Shushrut kumar Jain M, Savitha H and Shetty S: Application of medhya rasayana in astanga ayurveda: a review 2016; 5 (6): 190-92.

[46] Mahboubi M: Melisa officinalis and rosmarinic acid in management of 
memory functions and Alzheimer's disease 2019; 9(2): 47-52.

[47] Kamili C, Hemalatha E, Kandoti H, Konde A, Kumar M and Tummaluru R : Evaluation of memory -enhancing effect of flunarizine on active avoidance in experimental model of Alzheimer's disease through calcium homeostasis. Int $\mathrm{J}$ of Green Pharm 2019; 13(4): 348-52.

[48] Kamili C, Hemalatha E, Kandoti H, Konde A, Kumar M and Tummaluru R: Evaluation of memory-enhancing effect of flunarizine on active avoidance in experimental model of Alzheimer's disease through calcium homeostasis. Int $\mathrm{J}$ of Green Pharm 2019; 13(4): 348-52.

[49] Mahadik V and Wadkar K: Evaluation of cognition enhancing activity of ethanolic and aqueous extract of Vitis vinifera leaves in mice. Electronic Interdisciplinary International Research Journal 2018; 7: 137-43.

[50] Mahadik V, Patil K and Wadkar K: Sesbania grandiflora (agastya): a review on its phytochemical \& pharmacological profile. International Journal of Biological \& Pharmaceutical Research 2017; 9 (1): 1-6.
[51] Hiremath V and Handral M: Evaluation of memory enhancing activity of alcoholic extract of Cuscuta reflexa on experimentally induced dementia (Alzheimer's disease) in rodents. Indo American Journal of Pharmaceutical Research 2016; 6: 5512-20.

[52] Shrivastava S, Uthra C, Reshi $M$ and Shukla S: Protective role of Kaempferol against Acrylamide intoxication 2017; 7(1): 36-42. 